Contents List available at RAZI Publishing

\title{
ASSESSING ACCIDENT HOTSPOTS BY USING VOLUNTEERED GEOGRAPHIC INFORMATION
}

\author{
Golnoosh Farajollahi' ${ }^{1}$, Mahmoud Reza Delavar ${ }^{2 *}$ \\ ${ }^{1}$ MSc. Student in GIS Division, School of Surveying and Geospatial Eng., College of Eng., University of Tehran, Tehran, Iran. \\ ${ }^{2}$ Center of Excellence in Geomatic Eng. In Disaster Management, School of Surveying and Geospatial Eng., College of Eng., University of Tehran, Tehran, \\ Iran. \\ *Corresponding author Email: m.delavar@ut.ac.ir
}

This is an open access article distributed under the Creative Commons Attribution License, which permits unrestricted use, distribution, and reproduction in any medium, provided the original work is properly cited

\section{ARTICLE DETAILS}

\section{Article History:}

Received 6 July 2017

Accepted 6 October 2017

Available online 4 November 2017

\section{Keywords:}

Traffic volunteered information, analysis, points, making

\section{ABSTRACT}

Due to the ever-increasing number of vehicles, transportation issues, especially transportation safety have gained great importance. One of the social problems in the world, and particularly in developing countries, which each year imposes great casualties, and economic, social and cultural costs on society, is traffic accidents. Traffic accidents cause waste of time and assets and loss of human resources in society, therefore studies and measures to reduce accidents and damage caused by them, particularly in recent decades, has become important. One of the suggested ways to deal with the problem of car accidents is the modeling of accident-prone points, as by identifying these points, factors affecting accidents can be identified, and elimination of these factors leads to a reduction in accidents. Numerous studies have been conducted in this respect, using official police data to identify these points and performing necessary analysis on them. Official data has gaps and shortcomings. Using Volunteered Geographic Information to determine accident-prone venues can be a suitable answer to the problems of using official data. The aim of this study is the use of volunteered geographic information in relation to the accidents and their causes. By taking into account factors affecting traffic accidents in the study area, and determining the importance of each factor, as well as the severity-of-accidents parameter, and using the Expert Choice software, a decision-making software based on the hierarchical analysis, high-risk venues are determined, and the accident-prone points of the study area are specified.

\section{INTRODUCTION}

With the growing number of vehicles, road accidents increase. Economic impact of the accident in the early stages is small. Increase in the growth rate of the vehicles makes the economic impact of accidents much higher, and significantly affects the country's economy. Traffic accidents are one of the social problems in the world, which each year impose great casualties, and economic, social and cultural costs on society. This problem causes wasting of time and assets and loss of human resources in society. According to WHO report, one of the leading causes of death in the world is road accidents, killing more than 3 million people and injuring 20 to 50 million people every year [1]. In developing countries, due to deficiencies in transport infrastructure and higher number of accidents, this problem is of great importance and as a result, the direct and indirect costs in comparison with other countries are higher. Factors affecting the accidents are generally classified into human factors, environmental factors and vehicles [1]. Environmental factors consist of width and the geometry of the track, road signs and other means of track control, track lighting conditions, visual obstacles, lack of safeguards and so on. Human factors include lack of attention, illegal overtaking, tailgating and failure to comply with lateral distance. Statistic in our country showed that every 20 or 25-minute one person is dead as result of road accidents. Furthermore, based on the provided statistic from world health organization in 2012, Iran always was in the list of countries which have the highest number of death due to road accident, although the number is about decreasing but still is so high [2]. Purposeful and systematic reduction in number of accidents needs comprehensive road safety management. To reduce traffic accidents and improve road safety, it is crucial to understand how, where and when traffic accidents occurred. An improved understanding of spatial patterns of traffic accidents can make accident reduction efforts more effective [3]. Identification of the accident-prone points is the first step in road safety management process. Accident-prone points are sometimes known as dangerous places of road, high-risk places, accident- prone venues, places in need of improvement, and so on [4].

By collecting information about accidents that have taken place, some information about roads it's geometry properties and analyzing them, accident-prone areas are identified, and after identification of these areas, the strategies needed to reduce the number and severity of accidents is exercised that ultimately leads to reducing casualties caused by traffic accidents.

Traditional methods of hotspot detection by road professionals have included comparing count data at different locations and rating the areas by severity. However, the increase use of GIS has led to academics using sophisticated methods to quantify hotspots [5]. Many studies have been conducted to determine accidents hotspots and in these studies, official data has been used as a source for accidents information. Official data is traffic data from cameras and data recorded by the police. Given that installation of the cameras and collection and analysis of information obtained from them is expensive, and these cameras are not available in all urban areas, they do not have complete coverage of the entire city, and reports filed by police usually lack details. Furthermore, in many accidents, because of various reasons such as accident being minor, mutual agreement of participants, having no driver's license, long waiting time for police presence at the accident scene, escape of the culprit, and etc., police are not present at the scene of the accident and therefore no official report of the accident is available. Therefore, in this study, the use of volunteered geographic information is suggested in order to collect accident information.

In this study, accident-prone points are determined by hierarchical analysis method using Expert Choice software. First, volunteered geographic information related to accidents was collected, and by analyzing them and experts' opinions, effective factors in accidents were determined. Then, considering reasons and intensity of the accidents, accident-prone points were determined using aforementioned method. 
The structure of this study is that in the second part volunteered geographic information is defined. In the third part accident-prone areas, contributing factors in accidents and investigations in relation to the identification of these areas is described. In the fourth part research methods are proposed. In the fifth part the proposed method is implemented in Tehran and finally the conclusions and recommendations are expressed in Section 6

\subsection{Volunteered geographic information}

Internet has led to development of virtual communities and social networks, in which networks, data and information is shared. The first phase of the web evolution is known as Web1, in which information and services are offered only by specialists and webmasters [6]. Moving to the next step, which is known as Web2, is the circulation of concepts on the Internet without having specific knowledge and in this system, anyone can be a producer of information on the Internet [7]. Web2 is actually the transition from read-only web to read-write web. In this case, users are not only passive consumers and have the ability to share information and change it. [6] By development of this technology, and also given the need for communities to have location data and that the accessible, reliable and up-to-date data is needed, Volunteered Geographic Information (VGI) was defined. Goodchild has defined VGI as a combination of modern geography, collective intelligence and Web2 [7]. In this type of information, location, description and characteristics of data, are usually produced and circulated by ordinary citizens, whose activity is voluntary and unregulated, and no monetary goal or payment structure is present for collection of this data [8].

By this method, more detailed and complete data can be collected. Regarding accidents problem, by collecting the information by the people present at the scene of the accident, complete and detailed data about the accident can be obtained. Low cost and time needed to collect this information, the possibility of quickly updating it, more details about the accidents and its reasons, and easier access to this information, are the advantages of using VGI, and these advantages justify using this kind of information as a source for obtaining the accident data [8].

\subsection{Accident-prone points and factors affecting the accidents}

According to accident statistics worldwide, Secretary-General of the United Nations, on 11 May 2011, called the attention of the international community to adopt accurate scientific programs and reasonable investment in major economic and social planning to decrease traffic accidents, and improve road safety, and named this decade as the "decade of action for road safety". Furthermore, traffic accidents, with $32 \%$ share of the country's total deaths, are the leading cause of death in Iran. Considering these statistics, modeling accident-prone areas is essential. Although there is no accepted and general definition of accident-prone points, but these points can sometimes be defined as dangerous places of road, high-risk places, accident-prone venues, places in need of improvement, and etc [9].

accident-prone point has defined as "any point that has greater number of accidents due to local risk factors than other similar points". This definition means that the accident-prone points are points that in them, the geometric design and traffic risk factors have a significant role in the accidents, and accidents can be reduced by engineering solutions [10]. By determining these points, and identifying the factors influencing the accident, these factors can be eliminated to reduce accidents. Identification of accident-prone points requires an understanding of the factors influencing the accident. It should be noted that in this argument, we are concerned about location- related factors and therefore other factors such as specific weather conditions, status of driver and vehicle type are not considered (identification and prioritization). Specifications that can be taken into account to evaluate the performance of route safety are: average daily traffic (ADT), curve (length and radius), the direct route length, profile details (lane width, shoulder width), access routes density, dangers of roadside, sight distance, slope, pavement condition, speed limits and the difference between performance speed and design speed, difference in performance speed in successive sections, difference in needed and provided lateral friction, differences in performance velocity and average performance velocity, interference of vertical and horizontal arc, work pressure on the driver, and etc., which are often descriptive factors and usually show consistency of the geometric design [6]. Much research has been done in this regard in which official data is used as a source of information.
A scientist has addressed identification of accident-prone points using GIS in both space and time aspects, and for this reason has used kernel estimation density (KED) [11]. KED is a method to identify geographic patterns, which creates symmetrical surface around any point, and is able to identify accident-prone points by calculating density of each point. Some researcher outlines the general methods of detecting accident-prone points such as counting the number of accidents, severity of accidents and accident rate that are traditional methods, and suggests a combination of KED method and Moran's I and GetisOrdG as proposed method, and evaluates this method by testing it in roads in Turkey [12]. Evaluation result shows that, shown that the combination of KED method with Moran's Iworks best for direct paths, and combination of KED method with GetisOrd G is better for intersections. A researcher addresses the importance of information integration and its advantages, and inconsistency of data obtained from different sources, and states several methods to repair these inconsistencies [4]. Also, they proposed a solution for data selection from conflicting data, and finally, by resolving the inconsistencies, created the possibility of combining information. Other author deals with online prediction of traffic conditions by combining information obtained from various available sources [13]. In this study, data from global positioning systems, radio frequency identification and traffic cameras is used and weaknesses of each of them are investigated. Finally, by combining thesedatahave increased accuracy of traffic conditions predicament. Also, the hot spots in the highways in Afyonkarahisar administrative border were explored and determined with two different methods of Kernel Density analysis and repeatability analysis [14]. Subsequently, accident conditions at these hot spots were examined and in this study, they realized that the hot spots determined with two methods reflect really problematic places such as cross roads, junction points. Network kernel density estimation (NKDE) for detecting hotspots [15]. This method is a nonparametric approach for events distributed over one-dimensional space which facilitates estimating the density at any location in the study region not just at the location where the event occurs. A research describes a novel and extensive data collection and modeling effort to define accident models for two-lane road sections based on a unique combination of exposure, geometry, consistency and context variables directly related to the safety performance [16].

\section{PROPOSED METHOD}

First, volunteered geographic information related to accidents is extracted, using questionnaires distributed among people. Questionnaires are distributed among different people, and the needed information about accidents, including their location, their causes, and severity of accident (damage causing, injury causing, fatal) is extracted from the collected forms.

In this paper, the weight of each factor is calculated according to the collected statistics of the severity of an accident occurred and the opinion of experts, and finally accident-prone points in the study area are identified using the analytic hierarchy process (AHP). Decision-making process with a number of qualitative and quantitative criteria is facing many problems. AHP is one of the most comprehensive systems designed for multi-attribute decision making. AHP is a decision-making method by which decisions based on various criteria (multi-criteria) can be made. By AHP, first the decision-making problem is structured, then different options are compared on the basis of the criteria laid down in the decision making, and finally the priority of each of them is determined. By using this method:

- $\quad$ Decision-making process can be formulated;

- Various qualitative and quantitative criteria can be considered;

- Decision-making options can be considered;

- Sensitivity of the criteria and sub criteria can be analyzed.

In addition, the compatibility and incompatibility of the decision can be obtained with this method, which is the distinctive feature of this process. In general, this method is used in ranking, selection, assessment and prediction issues, all of which require decision-making. To achieve this, first a hierarchical structure was formed, and then the criteria which is the cause of the accident was determined. After that, according to the severity of accidents at the intersection, criteria were compared pair wise, priorities were assigned to them, and finally accident-prone points in the studied area were determined. In order to identify accident-prone points, Expert Choice software was used. This software is a multi-criteria decision support tool based on AHP, which has many capabilities, and in addition to the ability of designing hierarchy charts of decision-making, question 
designing, determining the preferences, and calculating the final weight, it is also capable of conducting the sensitivity analysis of decision-making to changes in the problem parameters. Also, in many cases this software uses charts and graphs to deliver results and performances.

In this paper, the study area is district 11 in Tehran. Criteria are selected from data collected through volunteered geographic information, and according to experts' opinion in accidents. Study criteria are:

- $\quad$ Short distance from population centers;

- Lack of the pedestrian overpass;

- Narrow street;

- $\quad$ High density of vehicles;

- Lack of proper traffic signals;

- Inappropriate intersection;

- Improper entrance and exit.

In addition to accident frequency, one of the factors effective in identify a place as the accident-prone point is the severity of the accidents in that place. Different researchers have mentioned different coefficients for the importance or severity factor of damage causing, injury causing and fatal accidents. Belgian Ministry of Transport uses coefficients of 1, 3 and 5 for damage causing, injury causing and fatal accidents and Portuguese Office of Transportation uses coefficients of 1,10 and 100 for damage causing, injury causing and fatal accidents, respectively $[17,18]$.

In this paper, coefficients of 1,3 and 5 were used to determine the severity of the accidents.

\section{IMPLEMENTATION}

Volunteered geographic information of the accidents for 1395 were collected through distributed questionnaires among ordinary people, employees of insurance institutes, and ambulance technicians of Tehran, Iran. This information contains the location of accidents and their attributes. One of the important attribute of accident information is Severity and by using it we determined hotspots of region 11 in Tehran. All of the information collected from form that distributed among of people and for digitizing accident information, we designed that form in Matlab programming environment.

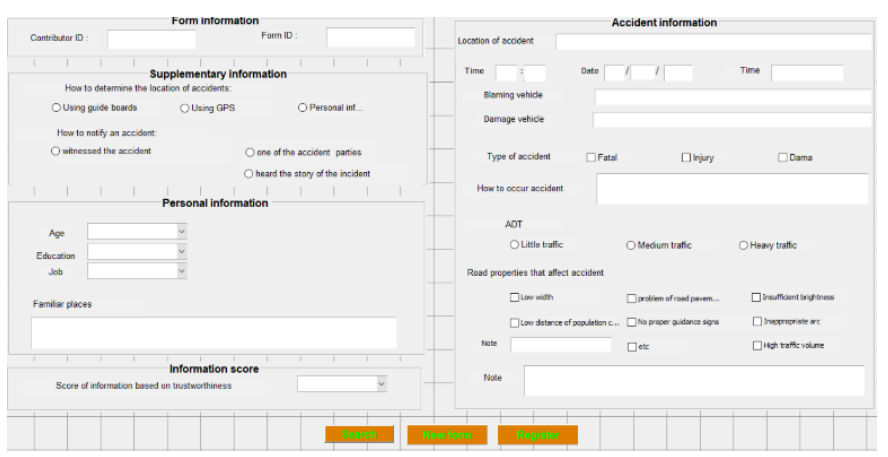

Figure 1: The locations of reported accidents enriched with attribute information.

Calculated weights based on the severity of accidents in different parts of the study area for accident causes were entered into software (Figure 2).

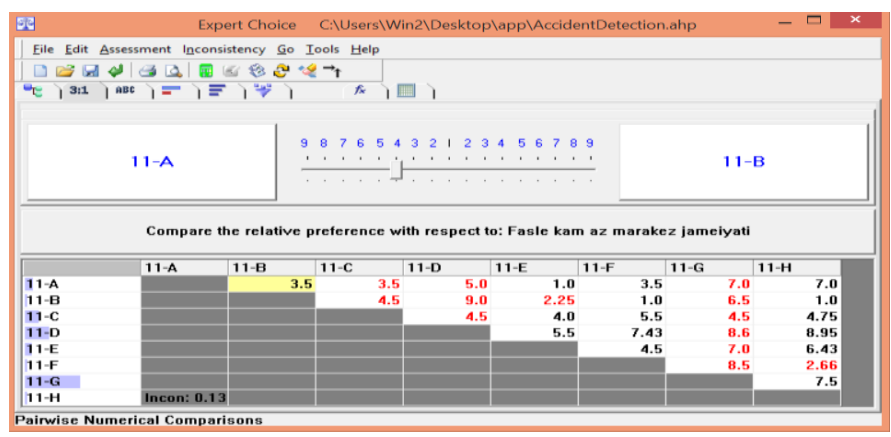

Figure.2: Numerical comparison of various points based on factors affecting accidents

Factors affecting the accidents are weighted relative to each other, using experts' opinion, and their relative importance and impact on traffic is determined as well (Figure 3).

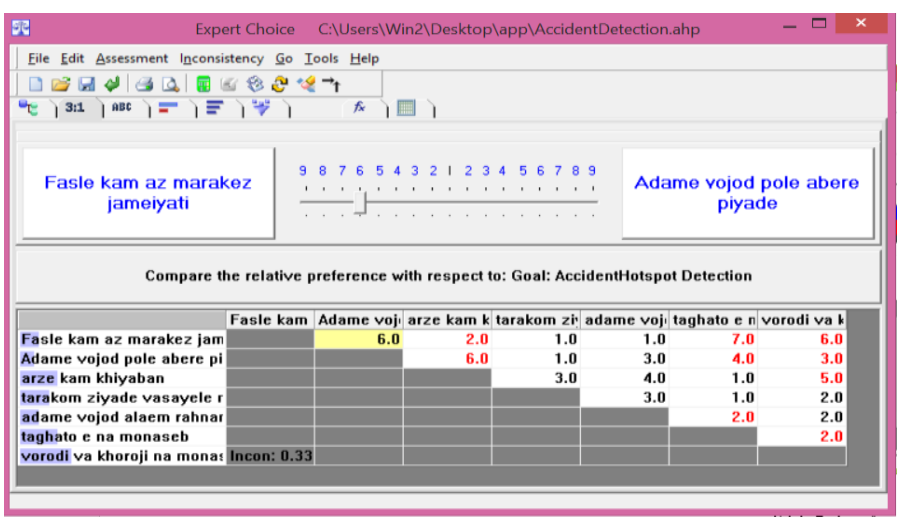

Figure 3: Comparison of factors affecting accidents

Finally, various points are compared pair wise and the results are displayed (Figure 4 and 5).

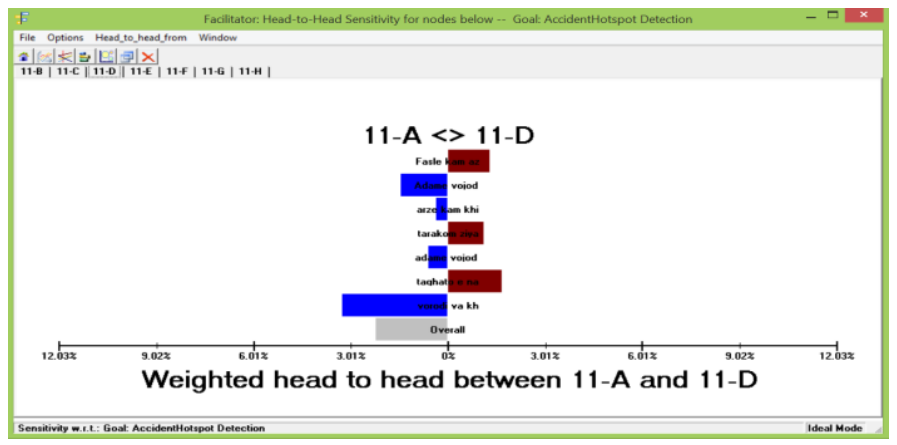

Figure 4: Pair wise comparison of different points in the area

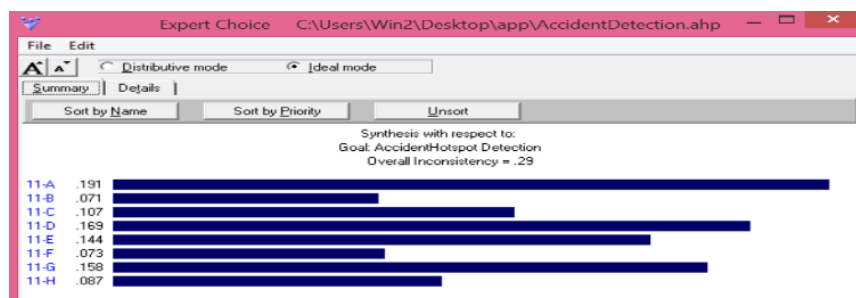

Figure 5: Accident prone potential of different parts of the study area

Based on the method used, areas A and D and G, which represent Qazvin Square, Jomhouri-Vali'Asr intersection, and Railway Square respectively, are determined as the most accident-prone places in District 11 of Tehran.

\section{CONCLUSION AND RECOMMENDATIONS}

Given the importance of traffic accidents in the world, especially in developing countries because of the large number of accidents, identification of the accident-prone points is essential in ensuring road safety. By determining these points, solutions and budget needed to fix road problems that cause road accidents can be produced. In this paper, the Analytic Hierarchy Process with the separation of accidents based on their cause was used to determine accident-prone points, and VGI was used for this analysis. The results of this study showed that Qazvin Square, 
Jomhouri-Vali'Asr intersection, and Railway Square, are the three most accident-prone places in District 11 of Tehran. This paper recommends quality control of the collected VGI for accident evaluation and their location, and also using other methods to investigate accident-prone points with VGI.

\section{REFERENCES}

[1] WHO. 2015. Global Status Report on Road Safety 2015, World Health Organization.

[2] Sehhat, S., Neurosci, I., and Shefaye, K. 2015. A report base on the observation regarding to percentage of death in road accident, 2 (4), e8.

[3] Xie, Z., and Yan, J. 2008. Kernel density estimation of traffic accidents in a network space Computers. Environment and Urban Systems Journal, 32 (5), 396-406.

[4] Dong, X., and Naumann,F. 2009. Fusion-resolving data conflict for integration. VLDB Endowment Journal, 2 (2), 1654-1655.

[5] Anderson, T. 2007. Comparison of spatial methods for measuring road accident hotspots: a case study of London. Journal of maps, 3 (1), 55-63.

[6] Cooper, A.K., Coetzee, S., Kaczmarek, I., Kourie, D.G., Iwaniak, A., and Kubik, T. 2011. Challenges for quality in volunteered geographical information, AfricaGEO 2011, Cape Town.

[7] Goodchild, M.F. 2007. Citizens as sensors: the world of volunteered geography GeoJournal, 69, 211-221.

[8] Al-Bakri, M., and Fairbairn, D. 2012. Assessing similarity matching for possible integration of feature classifications of geospatial data from official and informal sources. International Journal of Geographical Information Science, 26 (8), 1437-1456.

[9] Montella, A. 2010. A comparative analysis of hotspot identification methods. Journal of Accident Analysis and Prevention, 42, 571-581.
[10] Erdogan, M., Llci, V., Soysal, O., Korkmaz, A. 2015. A model suggestion for the determination of the traffic accident hotspot on the Turkish highway road network: a pilot study. Boletim de CienciasGeodesicas Journal, 21 (1), 169-188.

[11] Soltani, A., and Askari, S. 2014. Analysis of intra-urban traffic accidents using spatiotemporal visualization techniques. Transport and Telecommunication, 15 (3), 227-232.

[12] Elvik, R. 2007. State-of-the-art approaches to road accident black spot management and safety analysis of road networks, Report 883. Institute of Transport Economics, Oslo.

[13] Ma, Q., Liu, W., Sun, D. 2012. Hybrid multi-sensor data for traffic condition forecasting. Journal of Computers, 7 (8), 1870-1879.

[14] Erdogan, S., Yilmaz, I., Baybura, T., and Gullu, M. 2008. Geographical information systems aided traffic accident analysis system case study: city of Afyonkarahisar. Accident Analysis and Prevention Journal, 40 (1), 174 181.

[15] Shariat, Mohaymany, A., Shahri, M., and Mirbagheri, B. 2013. GISbased method for detecting high-crash-risk road segments using network kernel density estimation. Geo-spatial Information Science Journal, 16 (2) 113-119.

[16] Cafiso, S., Di Graziano, A., Di Silvestro, G., La Cava, G., and Persaud, B. 2010. Development of comprehensive accident models for two-lane rural highways using exposure, geometry, consistency and context Variables. Journal of Accident Analysis and Prevention, 42, 1072-1079.

[17] Geurts, K., Wets, G., Brijs, T., Vanhoof, K., and Karlis, D. 2006. Ranking and selecting dangerous crash locations: Correcting for the number of passengers and Bayesian ranking plots. Journal of Safety Research, 37, 83 $-91$.

[18] Elvik, R. A. 2008. Survey of operational definitions of hazardous road locations in some European countries. Journal of Accident Analysis and Prevention 40 (6), 1830-1835. 